\title{
The Great Deceleration and proposed alternative interpreta- tion of the Anthropocene
}

\author{
Retired nuclear scientist from Department of Nuclear Physics, The Australian National University, Canberra, ACT, 2601, Australia; \\ *Corresponding author, E-mail: ronwnielsen@gmail.com
}

(Received: March 24, 2020; Revised accepted: July 19, 2020)

https://doi.org/10.18814/epiiugs/2020/020076

Is the Anthropocene a new geological epoch and can its beginning be determined? The so-called Great Acceleration data, used repeatedly in support of the concept of the Anthropocene as a new geological epoch, are closely examined. They are supposed to be characterised by a clear intensification of growth (sharp increase, acceleration) in the mid-20th century. They revealed the opposite effect: they are characterised by decelerations either at precisely the same time when accelerations were expected or over the entire range of data, the phenomenon described here as the Great Deceleration. Implications of this study are two-folds: (1) contrary to expectations, these data cannot be used to determine the beginning of the Anthropocene and (2) the common deceleration questions whether humans alone can cause a transition to a new geological epoch. Investigation of the growth of the genus Homo in the past 2,000,000 years suggests that what is now called the Anthropocene could be just a natural continuation of the gradual evolution of human activities and impacts over a long time, without a sudden intensification and without a convincing evidence for a transition to a new geological epoch.

\section{Introduction}

This document presents results of an interdisciplinary study linking close examination of anthropogenic indicators with the question of whether Anthropocene is a new geological epoch. It is hoped that results presented here will contribute to the discussion of the concept of the Anthropocene. As pointed out by Bauer and Ellis (2018, p. 225), "there are many reasons why interdisciplinary discussions on the concept and utility of the Anthropocene should continue". Two important questions about this concept are: (1) Why should the Anthropocene be considered as one of the geological epochs? and (2) Where is the starting point of the Anthropocene?

The concept of the Anthropocene as a new geological epoch was not proposed by geologists. Furthermore, as noted by Finney and Edwards $(2015$, p. 6) this concept "did not derive from the stratigraphic record". It is based simply on the observation that humans have now strong impact on the environment and on the assumption that this strong impact causes transition to a new geological epoch. This is clearly stated in the original paper where the concept of the Anthropocene was introduced: 'Considering these and many other major and still growing impacts of human activities on earth and atmosphere, and at all, including global, scales, it seems to us more than appropriate to emphasize the central role of mankind in geology and ecology by proposing to use the term "anthropocene" for the current geological epoch' (Crutzen and Stoermer, 2000, p. 17). This statement contains the definition of the Anthropocene and its interpretation. The concept of the Anthropocene is made of two components: (1) a claim or recognition of the current strong anthropogenic impacts on the environment and (2) the interpretation of these impacts as causing a transition to a new geological epoch.

As for the second question, the starting point of the Anthropocene was originally proposed to have been "in latter part of the 18th century" (Crutzen and Stoermer, 2000, p. 17) but now it is assumed to have been around 1950 (Zalasiewicz et al., 2017). The beginning of the Anthropocene is supposed to be marked by a "sharp increase in human population, economic activity, resource use, transport, communication and knowledge-science-technology" (Costanza et al., 2007, p. 9, emphasis added). This supposed sharp increase is described as a sudden explosion in human enterprise around 1950 (Steffen et al., 2007), as a sudden or sharp increase in the rate of change around 1950 (Steffen et al., 2007; Gaffney and Steffen, 2017), as a sharp and dramatic increase in human activity around or after 1945 (Steffen et al., 2011), as a skyrocket increase after a long and slow growth and as a "breakpoint around 1950" (Steffen in Australian Broadcasting Corporation, 2016). It is also claimed that "every indicator of human activity underwent a sharp increase in rate around 1950" (Steffen et al., 2011, p. 849, emphasis added). If such is the case, many examples of abrupt accelerations should be easy to find and demonstrate.

Steffen et al. (2004) published excellent set of diagrams illustrating convincingly the rapid increase in the intensity of human activities and impacts. However, a rapid increase is not necessarily a sudden rapid increase. It is not necessarily a sharp increase at a certain time, as for instance around 1950. It is not necessarily a breakpoint. It could be a rapid increase resulting from a gradual, monotonic growth. In order to serve as a marker of the beginning of the Anthropocene, rapid 
increase has to contain a clear feature of a sudden acceleration at a certain time. Furthermore, this sudden acceleration should be characterising a large number of anthropogenic indicators. Monotonic growth cannot be used to determine the beginning of the Anthropocene because it does not contain any clearly distinguishable feature along its trajectory. Steffen at al. (2004) also claimed that every single diagram they presented displayed sharp acceleration around the 1950s. However, while the rapid increase is clearly shown in their set of diagrams, the evidence of the claimed systematic sharp accelerations in the 1950s is not demonstrated. Data published by Steffen at al. (2004) were later extended to more recent years and published as the Great Acceleration data (Broadgate et al., 2014). They play such a fundamental and iconic role in discussions of the concept of the proposed new geological epoch that they are described as the "trajectory of the Anthropocene" (Steffen et al., 2015). They were also suggested to be used to mark the beginning of the Anthropocene (Steffen et al., 2015; Zalasiewicz et al., 2017).

The objective of the study presented here was to examine the Great Acceleration data (Broadgate et al., 2014) to see whether they show systematic accelerations, which could be used to determine the beginning of the Anthropocene. Sources to each set of data are listed in the cited compilation (Broadgate et al., 2014). This analysis will be combined with the earlier analysis of the growth of the human population and of the economic growth (Nielsen, 2017a) based on a wider range of data (Taeuber and Taeuber, 1949; Cook, 1960; Deevey, 1960; Clark, 1968; Birdsell, 1972; Durand, 1974; Thomlinson, 1975; McEvedy and Jones, 1978; Biraben, 1980; Gallant, 1990; Trager, 1994; Haub, 1995; Hassan, 2002; Livi-Bacci, 2007; Maddison, 2010; US Census Bureau, 2019). These two indicators (growth of the human population and economic growth) are exceptionally important for the understanding of the concept of the Anthropocene because they are described by a significantly wider range of data than the remaining indicators and because they are closely linked with the overall intensity of anthropogenic activities and impacts. According to Waters et al. (2016, p. add 26222) the "increase in the consumption of natural resources is closely linked with the growth of the human population." The combined intensity of human activities is also reflected in the economic growth, which is closely linked with such anthropogenic indicators as the production and consumption of energy, water consumption, pollution of land and water, food production, land degradation, consumption of fertilizers, pollution of the atmosphere, loss of tropical forests, consumption of marine resources, ocean acidification, stratospheric ozone depletion, increased transportation, increased consumption of renewable and non-renewable resources, interference with nitrogen and phosphorus cycles, and more. Maybe all anthropogenic impacts and activities are embodied in and reflected by the economic growth but if not all, then many of them are. It is hard, maybe even impossible, to decouple economic growth from impacts on the environment caused by human activities. Recent study of this issue resulted in the following conclusion: "It is therefore misleading to develop growth-oriented policy around the expectation that decoupling is possible" (Ward et al., 2016, p. 10).

Growth of the human population and economic growth are strongly correlated (Maddison, 2010), so strongly that when going back in time, economic growth becomes quickly directly proportional to the growth of the human population. Using this property, De Long (1998) extended the estimates of the economic growth to $1,000,000 \mathrm{BC}$. Anthropogenic impacts on the environment cannot be explained solely by the growth of the human population. However, growth of the human population, which is described by the widest range of data, is so strongly linked with the economic growth and with the consumption of natural resources that it offers an excellent opportunity to place the concept of the Anthropocene in a broader context and to see it from a long perspective of time.

\section{Method of Analysis}

Method of analysis of the Great Deceleration data (Broadgate et al., 2014) consisted of the examination of the shapes of empirical distributions, examination of empirical growth rates and examination of reciprocal values of data (see Supplement). Mathematical analysis was not essential for the identification of accelerations or decelerations but it was added to assist in a better interpretation of data. Mathematical method of analysis of the Great Acceleration data was based on the analysis of growth rates (Nielsen, 2017b). For this analysis, data separated by small time intervals are needed. The Great Acceleration data fulfill perfectly this requirement. In this analysis, empirical growth rates are represented by distributions, which do not depend strongly on the range of data. This simple representation of growth rates is then used to generate more complicated mathematical descriptions of data by solving relevant but simple differential equations. Examples are presented in the Supplement. Full description of this method is presented in the cited reference (Nielsen, 2017b). The extended supplementary analysis of the growth of the human population was based primarily on the inspection of the reciprocal values of data (Nielsen, 2017a) because in this case, data before AD 1920 are not separated by small time intervals.

\section{Results and Discussion}

Results of the examination of the Great Acceleration data and of their mathematical analysis are presented in Table 1 and in Figs. 1 and 2. Indicators containing natural and anthropogenic components are marked by asterisk $(*)$. Additional information is presented in the Supplement. Growth trajectory of the genus Homo during the past 2,000,000 years is shown in Fig. 3. It includes the growth of Homo sapiens and it was in three stages, recognised earlier by Deevey (1960).

Even if humans have a significant impact on the environment, they do not necessarily have a strong enough impact on the Earth System as a whole to cause a transition to a new geological epoch. The issue of human impacts reflected in such activities as the development of science and technology, exploitation and waste of natural resources, and food production was discussed extensively by Steffen et al. (2004) and Nielsen (2006). It was also discussed by many other authors, presenting studies of individual aspects of numerous processes associated with the currently experienced human activities, for instance by Cui, et al. (2006), Delgado et al. (2012), Pacheco et al. (2013), Roder et al. (2013), Fletcher and Hughes (2017), DellaSala et al. (2018) and by He et al. (2019).

Critical issues associated with anthropogenic activities and impacts can be grouped in the following seven categories: (1) the rapid growth 
Table 1. Results of the examination of the Great Acceleration data (Broadgate et al., 2014) representing human activities and impacts

\begin{tabular}{|c|c|}
\hline Indicator & Change \\
\hline Global growth of population & Decelerated around 1960 \\
\hline Global economic growth & Decelerated around 1960 \\
\hline Global growth of urban population & Decelerated around 1960 \\
\hline Global consumption of primary energy & Decelerated around 1960 \\
\hline Global consumption of fertilizers & Decelerated around 1970 \\
\hline Global number of existing dams & Decelerated around 1970 \\
\hline Global consumption of water & Decelerated around 1980 \\
\hline Global telecommunication & Decelerated around 2000 \\
\hline Loss of atmospheric ozone & Decelerated around 1990 \\
\hline Global shrimp capture & Decelerated around 1990 \\
\hline Global loss of tropical forests & Decelerated around 1960 \\
\hline Global agricultural land area & Decelerated around 1960 \\
\hline Global foreign direct investment & Decelerating continuously \\
\hline Global paper production & Decelerating continuously \\
\hline Global transportation & Decelerating continuously \\
\hline Global international tourism & Decelerating continuously \\
\hline Global marine fish capture & Decelerating continuously \\
\hline Global temperature anomaly & Unpredictable trajectory ${ }^{(a)}$ \\
\hline Atmospheric concentration of $\mathrm{CO}_{2}$ & Accelerated in $1965^{(a)}$ \\
\hline Ocean acidification & Accelerated in $1965^{(\mathrm{a})}$ \\
\hline Atmospheric concentration of nitrous oxide & Accelerated in $1850^{(a)}$ \\
\hline Atmospheric concentration of methane & Decelerated in $1970^{(\mathrm{a})(\mathrm{b})}$ \\
\hline
\end{tabular}

${ }^{(a)}$ Contains natural and anthropogenic components. ${ }^{(b)}$ Reached a predictable maximum in 2006 but now is again increasing (Dlugokencky et al., 2019).

of the human population, (2) the diminishing land resources, (3) the diminishing water resources, (4) the destruction of the atmosphere, (5) the approaching energy crisis, (6) social decline, and (7) conflicts and increasing killing power (Nielsen, 2006). The fundamental problem with all these critical developments is that they are strongly coupled. Steffen et al. (2004) describe this complexity as the Planetary Machinery or the Earth System (singular). Many examples of anthropogenic activities and impacts could be discussed, but it is a broad topic that could easily lead to an extensive review of literature, which could be well outside the scope of this study. "No one can deny the role of the human species in altering the global environment, but so did many biological innovations, like the first burrowing animals at the beginning of the Cambrian Period, and the rise of terrestrial forests in the Carboniferous" (Gehling, 2018).

The issue of whether the Anthropocene is a new geological epoch can be competently resolved only by experts in this field of study. It has been suggested (Hamilton, 2015) that a compelling evidence might become available a million of years from now. However, interdisciplinary studies, such as presented here, can contribute to a better understanding of the currently experienced anthropogenic impacts and activities and thus to a better understanding of the concept of the Anthropocene. Extensive discussion of the analysis of individual distributions representing the Great Acceleration data (Broadgate et al., 2014) is presented in the Supplement. The striking feature of the Great Acceleration data is that there are no systematic accelerations around the 1950s. On the contrary, data for the purely anthropogenic indicators show systematic decelerations either sudden, around the time when sudden accel- erations were expected, or continuous over the entire range of data, the phenomenon described here as the Great Deceleration. There is no systematic intensification that could be used to determine the beginning of the Anthropocene around 1950, as suggested by Zalasiewicz et al. (2017). The only two indicators that extend over an exceptionally long time in this group of the Great Acceleration data are growth of the human population and economic growth. They show that there was also no sudden intensification of growth that could be used to determine the beginning of the Anthropocene around 1800 as originally suggested by Crutzen and Stoermer (2000).

Looking from a longer perspective of time, data and the accompanying mathematical analysis presented in Fig. 3, show a remarkably steady growth of the human (hominine) population. During that long time, there were only two major changes in the pattern of growth: between 46,000 and 27,000 BC and between $425 \mathrm{BC}$ and $\mathrm{AD} 510$. The first transition was marked by a significant acceleration but it occurred over about 19,000 years. The second transition was a significant deceleration but again it occurred over a long time of approximately 1000 years. Growth of the genus Homo in the past 2,000,000 years was hyperbolic for about $99 \%$ of time (Nielsen, 2017a). The strong irregularity between the second and third stage is caused simply by a transition from a fast to a slow hyperbolic growth. What is now called the Anthropocene is right at the end of this continuous and steady growth and it is not marked by an unusual acceleration but by a deceleration (US Census Bureau, 2019). Even if the assumed beginning of the Anthropocene is placed "in the later part of the 18th century" (Crutzen and Stoermer, 2000 , p. 17) it is an event that lasted so far for less than $0.01 \%$ of the 

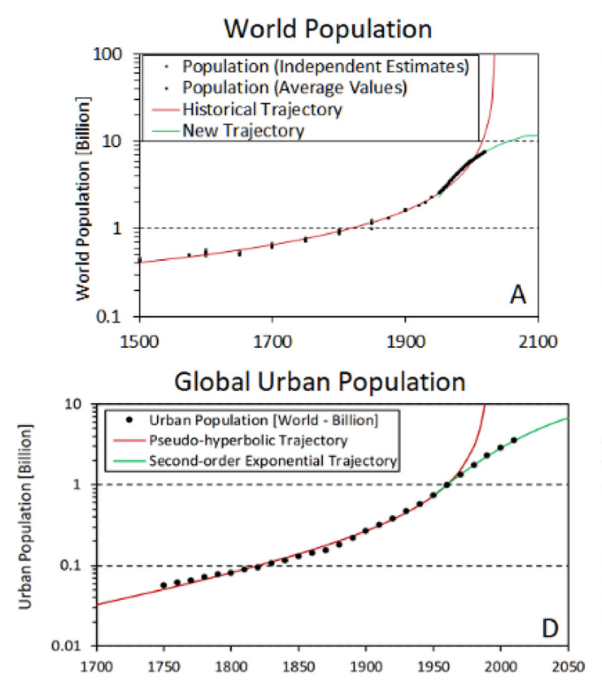

Global Number of Large Dams
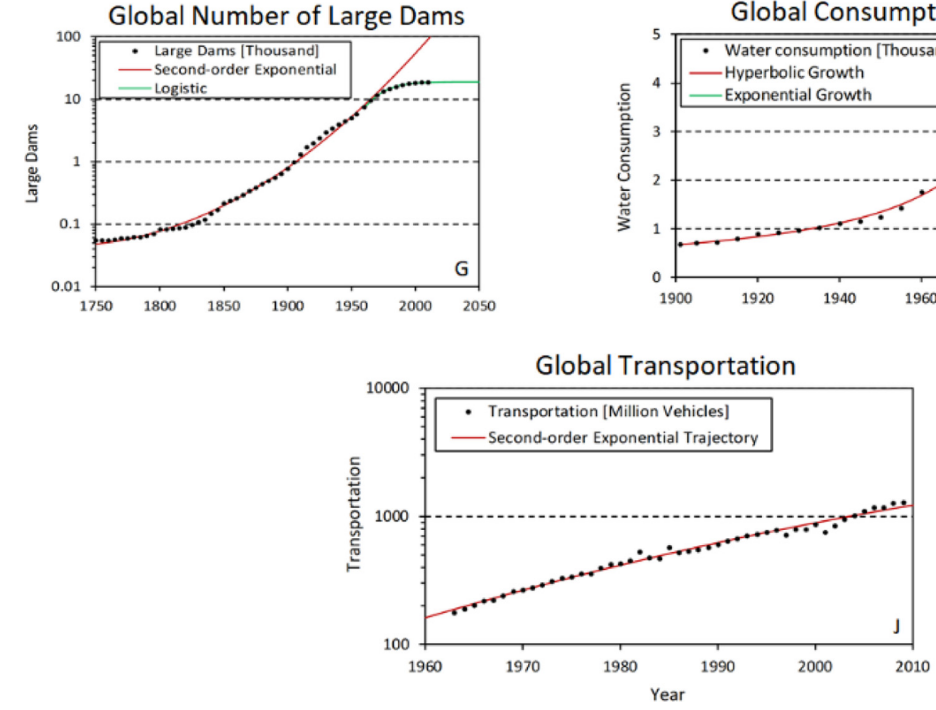

World Economic Growth

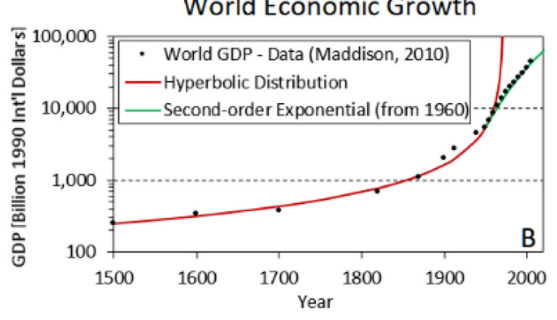

World Energy Consumption

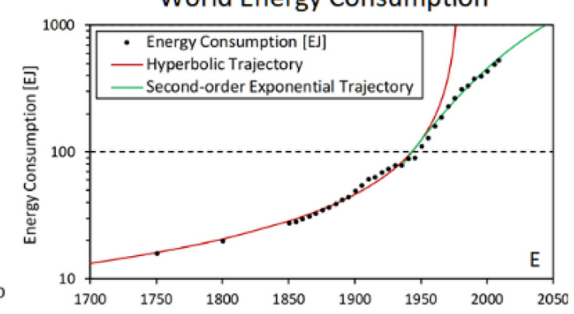

Global Consumption of Water

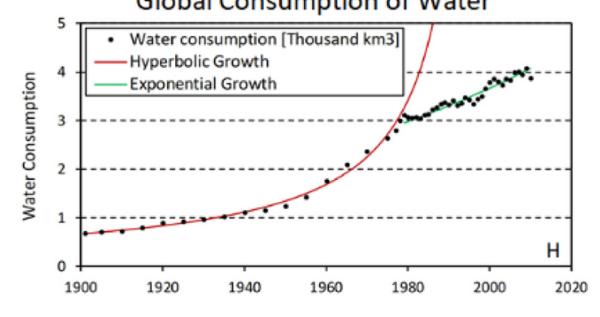

Global Foreign Direct Investment

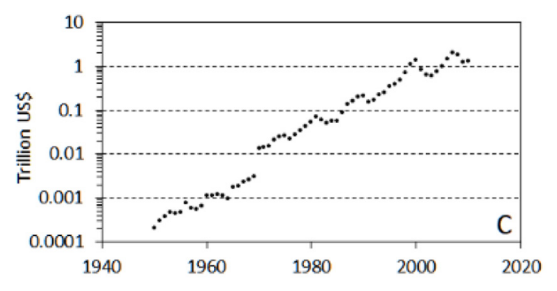

Global Consumption of Fertilizers

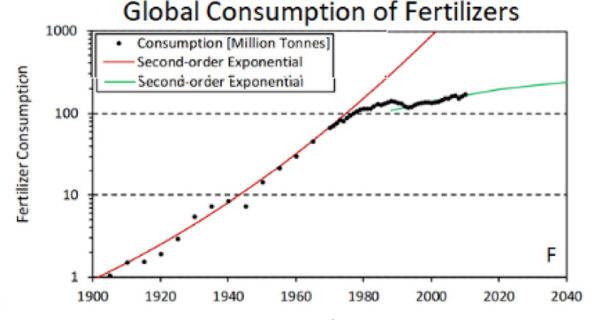

Global Paper Production

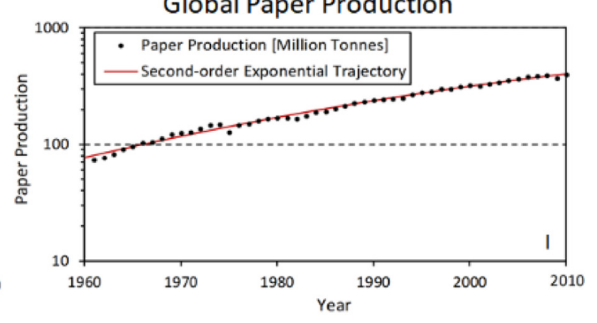

Global Telecommunication

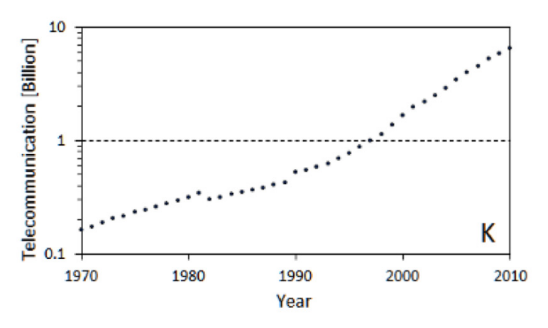

Figure 1. (A) Global growth of the human population: decelerated around 1960. (B) World economic growth: decelerated around 1960. (C) Global foreign direct investment: vertical displacement of data makes the analysis difficult but empirical growth rate suggests continuous deceleration (see Supplement). (D) Global growth of urban population: decelerated around 1960. (E) Global consumption of primary energy: decelerated around 1960. (F) Global consumption of fertilizers: decelerated around 1970. (G) Global number of existing dams: decelerated around 1970. (H) Global consumption of water: decelerated around 1980. (I) Global paper production: decelerating continuously over the entire range of data. (J) Global transportation: empirical growth rate suggests continuous deceleration (see Supplement). (K) Global telecommunication: vertical displacement of data makes the analysis difficult but growth rate data (see Supplement) show a clearly accelerating growth after the vertical displacement followed by deceleration in around 2000.

total time of the past anthropogenic history (Harmand et al., 2015). Even if we start counting from the time of the emergence of Homo sapiens (Weaver et al., 2008), the Anthropocene represents less than $0.1 \%$ of the total time. What kind of a concentrated force would be required to cause a geological transition during such a small fraction of time? The new concept of placing the commencement of the Anthropocene around 1950 (Zalasiewicz et al., 2017) makes it even more difficult to accept. Now even a stronger force would be required to have a detectable geological impact, but the analysis of the Great Acceleration data (Broadgate et al., 2014) indicates that anthropogenic forces started to become weaker from around 1950. The evidence in data does not give a clear support for the concept of the Anthropocene as a new geological epoch.

There are no systematic data describing anthropogenic activities and impacts over thousands or millions of years, which could be analysed in the same way as the Great Acceleration data (Broadgate et al., 2014). However, close examination of the growth of the human (hominine) population over the past 2,000,000 years suggests an alternative interpretation of the Anthropocene. It is a process that could be perhaps viewed from a longer perspective of time as a natural continuation of the gradually evolving human (hominine) activities and impacts on the environment. The beginning of this process would be hard or even impossible to determine but it could be perhaps defined as the time of the emergence of Homo sapiens or maybe even of genus Homo. What is now called the Anthropocene could be a beginning of just a new stage in human history without geological consequences, the beginning of another "age" similar to the previous Stone Age, Bronze Age or Iron Age. Maybe it could be called a Techno Age and it does not mat- 

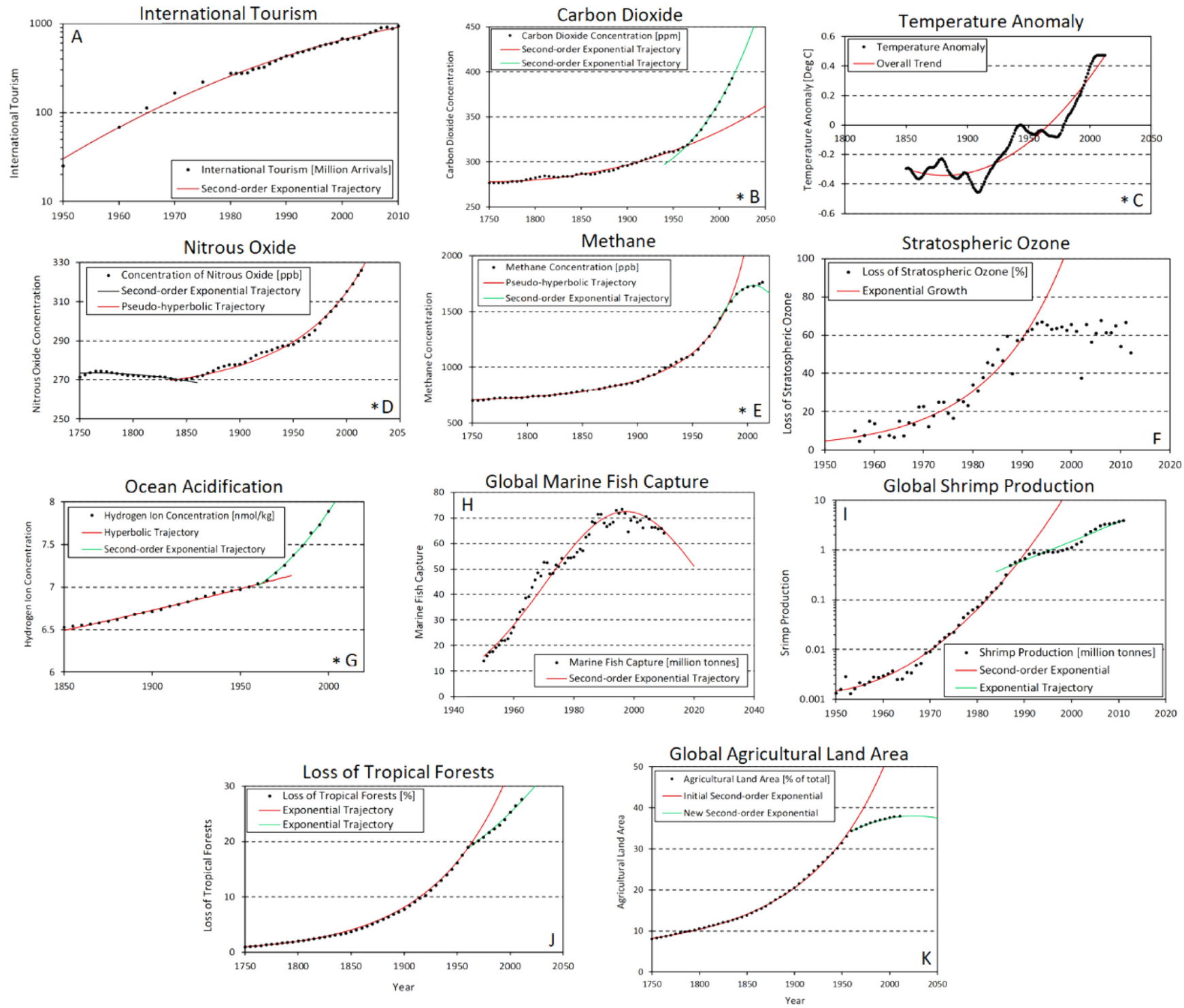

Figure 2. (A) Global international tourism: continuous deceleration over the entire range of data. (B) Atmospheric concentration of carbon dioxide: accelerated around 1965. (C) Global temperature anomaly: mathematically unpredictable growth. (D) Atmospheric concentration of nitrous oxide: accelerated around 1850. (E) Atmospheric concentration of methane: decelerated around 1970 but now increasing again. (F) Loss of stratospheric ozone: decelerated around 1990. (G) Ocean acidification: accelerated around 1965. (H) Global marine fish capture: decelerating over the entire range of data. (I) Global shrimp production: decelerated around 1990. (J) Global loss of tropical forests: decelerated around 1960. (K) Global agricultural land area: decelerated around 1960. Indicators containing natural and anthropogenic contributions are marked by asterisk (*).

ter where precisely its beginning is placed. A similar broader interpretation of the Anthropocene was also proposed by Ruddiman (2003, 2017), Beach et al. $(2015,2019)$ and Edgeworth et al. (2015).

In order to understand the current strong anthropogenic impacts on the environment it is important to notice that while the steady growth of the human population is closely correlated with the steady economic growth (De Long, 1998; Maddison, 2010; cf Figs. 1A and 1B), and thus with the steadily increasing consumption of natural resources (Waters et al., 2016), there is no such clear correlation with the apparently sudden surge in the progress of science and technology. Industrial Revolution (around 1800) with its unprecedented and rapid technological and scientific advances did not boost the trajectories of the economic growth and of the growth of the human population (see
Figs. 1A and 1B). Furthermore, the continuing technological innovations and scientific discoveries had no impact on preventing the diversion of the economic growth and of the growth of the human population to slower trajectories from around 1960.

\section{Conclusions}

The aim of the study presented here was to check whether the socalled Great Acceleration data (Broadgate et al., 2014) show the expected abrupt accelerations, which could be used to determine the beginning of the Anthropocene. Data alone (without their mathematical analysis) demonstrate that there is no supporting evidence in the purely 


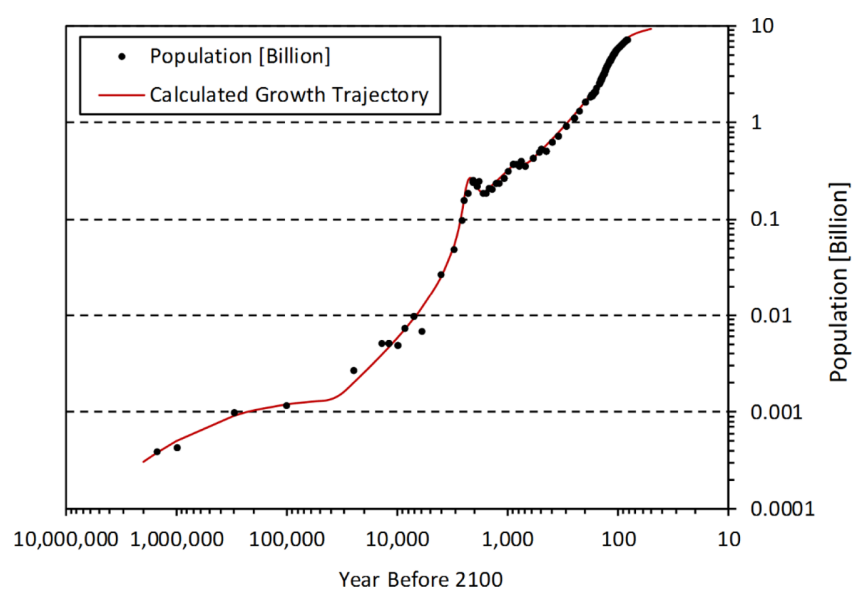

Figure 3. Growth of the genus Homo, including Homo sapiens, in the past 2,000,000 years (Nielsen, 2017a). If, as it can be expected, the intensity of human activities and impacts increases with the growth of the human population (Waters et al., 2016), then this pattern of growth suggests their steady evolution over a long time, the process transcending the Pleistocene and Holocene epochs. What is called the Anthropocene, has no clearly determinable beginning in recent years. It appears to be a part of a long human (hominine) history without necessarily causing a geological transition. Its beginning could be perhaps traced to the onset of Homo sapiens or even earlier to the beginning of the genus Homo.

anthropogenic indicators for claiming the beginning of the Anthropocene around 1950 (Zalasiewicz at al., 2017) or around 1800 (Crutzen and Stoermer, 2000), or at any other time (see Table 1, Figs. 1 and 2 and the Supplement). Mathematical analysis confirms and reinforces this conclusion.

Data alone demonstrate also that for the purely anthropogenic indicators there was either abrupt deceleration in human activities and impacts in the mid-20th century or a continuous deceleration over the entire range of time for which data are available. This feature is described here as the Great Deceleration. Thus, the characteristic feature of the Great Acceleration data (Broadgate et al., 2014) is the Great Deceleration. The Great Deceleration should not be interpreted as a solution to the currently experienced global environmental problems. It might be increasing a chance of finding suitable solutions but it does not serve as a guarantee.

Examination of the growth of the human (hominine) population from around 2,000,000 $\mathrm{BC}$, suggests that what is now called the Anthropocene could be just a natural continuation of a process that transcends the Pleistocene and Holocene epochs. The Anthropocene might be just a part of the human history without being a part of a geological processes. Human impacts and activities are now strong but it is questionable whether they are strong enough to cause a transition to a new geological epoch, particularly because, in general, they were becoming weaker from the 1950s or even earlier. However, they might be unleashing far stronger natural forces. Combined effects of all these processes might become clear in the future. Evidence for the Anthropocene understood as representing strong anthropogenic impacts on the environment, but without a determinable beginning, is convincing but its postulated geological impact is questionable. The relatively brief anthropogenic domination, even if measured in millions of years, might be terminated by a partial or a total self-destruction of human species without any profound alteration of natural processes that prevailed over a much longer time.

\section{Data Availability}

Great Acceleration data: Broadgate et al. (2014) and references therein. Historical estimates of the world population: compilations presented by Manning (2008) and US Census Bureau (2018) and additional references listed in the Introduction. Population data from 1950: US Census Bureau (2019). Economic growth data: Maddison (2010).

\section{Acknowledgement}

I want to thank Paul Crutzen for reading and endorsing results of this work. I am grateful to Matt Edgeworth, Jim Gehling, Stan Finney, Frank Oldfield, Will Steffen and Nora Noffke for their comments. Encouraging support from Dan deB. Richter, Jai Syvitski, Phil Gibbard, Mike Walker, and John Low is also gratefully appreciated. The author declares no conflict of interest. This research was carried out without financial support.

\section{References}

Australian Broadcasting Corporation, 2016, The Anthropocene: a new age of humans. http://www.abc.net.au/catalyst/stories/4574615.htm [accessed 21st March 2020].

Bauer, M., and Ellis, E.C., 2018, The Anthropocene Divide: Obscuring Understanding of Social-Environmental Change. Current Anthropology, v. 59, pp. 209-227, doi:10.1086/697198

Beach, T., Luzzadder-Beach, S., Cook, D., Dunning, N., Kennett, D.J., Krause, S., Terry, R., Trein, D., and Valdez, F., 2015, Ancient Maya impacts on the Earth's surface: An early Anthropocene analog? Quaternary Science Reviews., v. 124, pp. 1-30, doi:org/10.1016/j.quascirev.2015.05.028

Beach, T., Luzzadder-Beach, S., Krause, S., Guderjan, T., Valdez Jr., F., Fernandez-Diaz, J.C., Eshleman, S., and Doyle, C., 2019, Ancient Maya wetland fields revealed under tropical forest canopy from laser scanning and multiproxy evidence. Proceedings of the National Academy of Sciences, v. 116, pp. 21469-21477, doi:10.1073/pnas.1910553116

Biraben, J.-N., 1980, An Essay Concerning Mankind's Evolution. Journal of Human Evolution, v. 9, pp. 655-663, doi:10.1016/0047-2484(80) 90099-8

Birdsell, J.B., 1972, Human Evolution: An Introduction to the New Physical Anthropology. Rand Mc Nelly, Chicago, 582 p.

Broadgate, W., Owen Gaffney, O., Deutsch, L., Ludwig, C., and Steffen, W., 2014, The Great Acceleration data. http://www.igbp.net/download/18.950c2fa1495db7081ebc7/1421334707878/IGBPGreatAccelerationdatacollection.xlsx [accessed 21st March 2020].

Clark, C., 1968, Population Growth and Land Use. St Martin's Press, New York, NY, $200 \mathrm{p}$.

Cook, R.C., 1960, World Population Growth. Law and Contemporary Problems, v. 25, pp. 379-388.

Costanza, R., Graumlich, L.J., and Steffen, W., 2007, Sustainability or Collapse: Lessons from Integrating the History of Humans and the Rest of Nature. In: Costanza, R., Graumlich, L., and Steffen, W. (Eds.), Sustainability or Collapse? The MIT Press, Cambridge, MA, pp. 3-19.

Crutzen, P.J., and Stoermer, E.F., 2000, The 'Anthropocene'. IGBP Newsletter, v. 41, pp. 17-18.

Cui, X., Graf, H-F., Langmann, B., Chen, W., and Huang, R., 2006, Cli- 
mate impacts of anthropogenic land use changes on the Tibetan Plateau. Global and Planetary Change, v. 54, pp. 33-56, doi:10.1016/j.gloplacha.2005.07.006

Deevey, E.S. Jr, 1960, The human population. Scientific American, v. 203, pp. 195-204.

Delgado, J., Boski, T., Nieto, J.M., Pereira, L., and García-Tenorio, R., 2012, Sea-level rise and anthropogenic activities recorded in the late Pleistocene/Holocene sedimentary infill of the Guadiana Estuary (SW Iberia). Quaternary Science Reviews, v. 33, pp. 121-141, doi:10.1016/ j.quascirev.2011.12.002

DellaSala, D.A., Goldstein, M.I., Elias, S., Jennings, B., Lacher, T.E., Mineau, P., and Pyare, S., 2018, The Anthropocene: How the great acceleration is transforming the planet at unprecedented levels. In DellaSala, D.A., and Goldstein, M.I. (Eds.), Encyclopedia of the Anthropocene, Elsevier, Oxford, UK, pp. 1-7.

De Long, J.B., 1998, Estimates of World GDP One Million B.C - Present. http://delong.typepad.com/print/20061012_LRWGDP.pdf [accessed 12 June 2020].

Dlugokencky, E.J., Crotwell, A.M., Lang, P.M., and Mund, J.W., 2019, Atmospheric Methane Dry Air Mole Fractions from quasi-continuous measurements at Barrow, Alaska and Mauna Loa, Hawaii. ftp://aftp. cmdl.noaa.gov/data/trace_gases/ch4/in-situ/surface/[accessed 21st March 2020].

Durand, J.D., 1974, Historical Estimates of World Population: An Evaluation. Analytical and Technical Reports, Number 10, University of Pennsylvania, Population Center, Philadelphia, PA, 72 p.

Edgeworth, M., de B Richter, D., Waters, C., Haff, P., Neal, C., and Price, S.J., 2015, Diachronous beginning of the Anthropocene: The lower bounding surface of anthropogenic deposits. The Anthropocene Review, v. 2, pp. 33-58, doi:10.1177/2053019614565394

Finney, S.C., and Edwards. L.E., 2015, The "Anthropocene" epoch: Scientific decision or political statement? GSA Today, v. 26, pp. 4-10, doi:10.1130/GSATG270A.1

Fletcher, W.J., and Hughes, P.D., 2017, Anthropogenic trigger for Late Holocene soil erosion in the Jebel Toubkal. Catena, v. 149, pp. 713726, doi:10.1016/j.catena.2016.03.025

Gaffney, O., and Steffen, W., 2017, The Anthropocene equation. Anthropocene. Review, v. 4, pp. 53-61, doi:10.1177/2053019616688022

Gallant, R.A., 1990, The Peopling of Planet Earth: Human Growth through the Ages. Macmillan Publishing Company, New York, NY, 163 p.

Gehling, J.G., 2018. Private communication.

Hamilton, C., 2015, Getting the Anthropocene so wrong. The Anthropocene Review, v. 2, pp. 102-107.

Harmand, S., Lewis, J.E., Feibel, C.S., Lepre, C.J., Prat, S., Lenoble, A., Boës, X., Quinn, R.L., Brenet, M., Arroyo, A., Taylor, N., Clément, S., Daver, G., Brugal, J-P., Leakey, L., Mortlock, R.A., Wright, J.D., Lokorodi, S., Kirwa, C., Kent, D.V., and Roche, H., 2015, 3.3-million-year-old stone tools from Lomekwi 3, West Turkana, Kenya. Nature, v. 521, pp. 310-315, doi:10.1038/nature14464

Hassan, F.A., 2002, Population Dynamics. In: Barker, G. (Ed.), Companion Encyclopedia of Archaeology, Routledge, London, pp. 672-713.

Haub, C., 1995, How Many People Have Ever Lived on Earth? Population Today, v. 23, pp. 4-5.

He, Y., Wu, Y., Lu, C., Wu, M., Chen, Y., and Yang, Y., 2019, Morphological change of the mouth bar in relation to natural and anthropogenic interferences. Continental Shelf Research, v. 175, pp. 42-52, doi:10.1016/ j.csr.2019.01.015

Livi-Bacci, M., 2007, A Concise History of World Population (2nd edition). Blackwell Publishers, Malden, MA, 296 p.

Maddison, A., 2010, Historical Statistics of the World Economy: 1-2008 AD. http://www.ggdc.net/maddison/Historical Statistics/horizontalfile_02-2010.xls [accessed 21st March 2020].

Manning, S., 2008, Year-by-Year World Population Estimates: 10,000 B.C. to 2007 A.D. http://www.scottmanning.com/content/year-by-year-worldpopulation-estimates/ [accessed 21st March 2020].
McEvedy, C., and Jones, R., 1978, Atlas of World Population History. Penguin Books Ltd., Harmondsworth, Middlesex, England, 368 p.

Nielsen, R. 2006, The Green Handbook: Seven trends shaping the future of our planet. St. Martin's Press, New York, 365 p.

Nielsen, R.W., 2017a, Economic Growth and the Growth of Human Population in the Past 2,000,000 Years. Journal of Economic Bibliography, v. 4, pp. 128-149.

Nielsen, R.W., 2017b, Application of Differential Equations in Projecting Growth Trajectories. Journal of Economic Bibliography, v. 4, pp. 203221.

Pacheco, F.A.L., Landim, P.M.B., and Szocs, T., 2013, Anthropogenic impacts on mineral weathering: A statistical perspective. Applied Geochemistry, v. 36, pp. 34-48.

Roder, C., Wu, Z., Richter, C., and Zhang, J., 2013, Coral reef degradation and metabolic performance of the scleractinian coral Porites lutea under anthropogenic impact along the NE coast of Hainan Island, South China Sea. Continental Shelf Research, v. 57, pp. 123-131, doi:10.1016/ j.csr.2012.11.017

Ruddiman, W.F., 2003, The Anthropocene Greenhous Era Began Thousand of Years Ago. Climatic Change, v. 61, pp. 261-293, doi:10.1023/ B:CLIM.0000004577.17928.fa

Ruddiman, W., 2017, Geographic evidence of the early anthropogenic hypothesis. Anthropocene, v. 20, pp. 4-14, doi:10.1016/j.ancene. 2017.11.003

Steffen, W, Sanderson. A., Tyson, P.D., Jager, J., Matson, P.A., Moore III, B., Oldfield, F., Richardson, K., Schellnhuber, H.J., Turner II, B.L., and Wasson, R.J., 2004, Global Change and the Earth System: A Planet Under Pressure. The IGBP Book Series. Springer-Verlag, Berlin, Heidelberg, New York, 336 p.

Steffen, W., Crutzen, P.J., and McNeill, J.R., 2007, The Anthropocene: Are Humans Now Overwhelming the Great Forces of Nature? Ambio, v. 36, pp. 614-621, doi:10.1579/0044-7447(2007)36[614:taahno]2.0.co;2

Steffen, W., Grinevald, J., Crutzen, P., and McNeill, J., 2011, The Anthropocene: conceptual and historical perspectives. Philosophical Transactions of the Royal Society A: Mathematical, Physical and Engineering Sciences, v. 369, pp. 842-867, doi:10.1098/rsta.2010.0327

Steffen, W., Broadgate, W., Deutsch, L., Gaffney, O., and Ludwig, C., 2015, The trajectory of the Anthropocene. The Great Acceleration. The Anthropocene Review, v. 2, pp. 81-98, doi:10.1177/2053019614564785

Taeuber, C., and Taeuber, I.B., 1949, World Population Trends. Journal of Farm Economics, v. 31, pp. 237-250.

Thomlinson, R., 1975, Demographic Problems, Controversy Over Population Control (2nd edition). Dickenson Pub., Encino, CA, 244 p.

Trager, J., 1994, The People's Chronology: A Year-by-Year Record of Human Events from Prehistory to the Present. Henry Holt and Company, New York, NY, 1251 p.

US Census Bureau, 2018, Historical Estimates of World Population. https:/ /www.census.gov/data/tables/time-series/demo/international-programs/historical-est-worldpop.html [accessed 21st March 2020].

US Census Bureau, 2019, International Data Base. https://www.census.gov/ programs-surveys/international-programs/about/idb.html [accessed 21st March 2020].

Ward, J.D., Sutton, P.C., Werner, A.D., Costanza, R., Mohr, S.H., and Simmons, C.T., 2016, Is Decoupling GDP Growth from Environmental Impact Possible? PLoS ONE, v. 11, pp. 1-14, doi:10.1371/journal.pone.0164733

Waters, C.N., Zalasiewicz, J., Summerhayes, C., Barnosky, A.D., Poirier, C., Gałuszka, A., Cearreta, A., Edgeworth, M., Ellis, E.C., Ellis, M., Jeandel, C., Leinfelder, R., McNeill, J.R., deB. Richter, D., Steffen, W., Syvitski, J., Vidas, D., Wagreich, M., Williams, M., Zhisheng, A., Grinevald, J., Odada, E., Oreskes, N., and Wolfe, A.P., 2016, The Anthropocene is functionally and stratigraphically distinct from the Holocene, Science, v. 351, pp. aad2622-1- aad2622-10, doi:10.1126/science.aad2622

Weaver, T.D., Roseman, C.C., Stringer C.B., 2008, Close correspondence between quantitative and molecular-genetic divergence times for Neander- 
thals and modern humans. Proceedings of the National Academy of Sciences of the United States of America, v. 105, pp. 4645-4649, doi:10.1073/pnas.0709079105

Zalasiewicz, J., Waters, C.N., Summerhayes, C., Wolfe, A.P., Barnosky, A.D., Cearreta, A., Crutzen, P., Ellis, E., Fairchild, I.J., Gałuszka, A.,
Haff, P.K., Hajdas, I., Head, M. J., do Sul, I., Jeandel, C., Leinfelder, R., McNeill, J.R., Neal, C., Odada, E., Oreskes, N., Steffen, W., Syvitski, J., Vidas, D., Wagreich, M., and Williams, M., 2017, The Working Group on the Anthropocene: Summary of evidence and interim recommendations. Anthropocene, v. 19, pp. 55-60, doi:10.1016/j.ancene. 2017.09.001

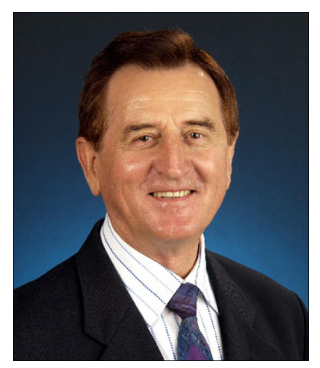

Ron W. Nielsen, aka Jan Nurzynski, is a retired nuclear scientist. After his retirement he became interested in environmental issues. He published a book containing a broad range of data to help to understand the ongoing human activities and impacts. This book was endorsed by Paul Crutzen, who introduced him to the concept of the Anthropocene. Ron Nielsen extended his work by carrying out extensive analysis of two crucial anthropogenic indicators: growth of the human population and economic growth, both regional and global. He introduced the concept of the force of growth and used it to explain the mechanism of hyperbolic growth of the human population and of economic growth. He also formulated mathematical procedure of data analysis and forecasting by using the force of growth. 